\title{
114. Geochemical Studies of a 200 meters Core Sample from Lake Biwa
}

\section{The Determination of Carbon and Nitrogen}

\author{
By Tadashiro KoYAMA
}

Water Research Laboratory, Faculty of Science, Nagoya University

(Comm. by Kenjiro Kimura, M. J. A., Sept. 12, 1972)

Analytical method of carbon and nitrogen in the core sample.

Preparation of samples. Sediment samples of about $10 \mathrm{~g}$ were taken from frozen sediments $5 \mathrm{~cm}$ thick at various depths of the core sample. The samples were dried at $110^{\circ} \mathrm{C}$ and then ground to a fine powder with an agate mortar.

Preparation of samples treated with hydrogen peroxide. Each of the dried samples $(0.2 \mathrm{~g})$ was placed in a beaker. To the beaker $30 \mathrm{ml}$ of water and $10 \mathrm{ml}$ of a hydrogen peroxide solution (30\%) were added, and then it was heated on a boiling-water bath. After 30,60 , and 90 minutes, $5-\mathrm{ml}$ portions of the hydrogen peroxide solution were added in order to decompose the organic matter in the samples. The content in the beaker was then transferred to a centrifuge tube (capacity, $50 \mathrm{ml}$ ) and centrifuged at $2000 \mathrm{rpm}$ for $5 \mathrm{~min}$ utes. After the supernatant had then been decanted out, $50 \mathrm{ml}$ of distilled water was added to the tube to wash out the residue. The washing, centrifugation, and decantation of the supernatant were repeated three times in order to remove the decomposed matter from the residue. The residue was transferred to a watch glass with a

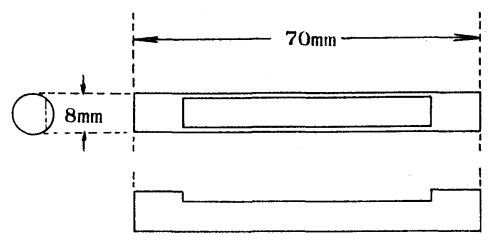

(a)

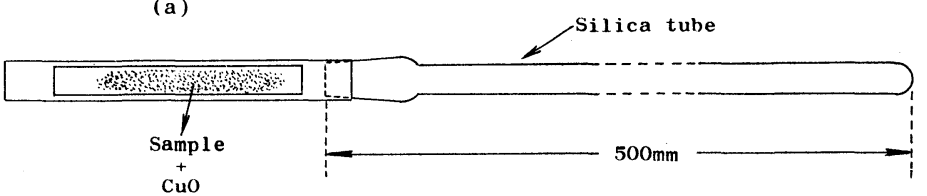

(b)

Fig. 1. Combustion boat. 


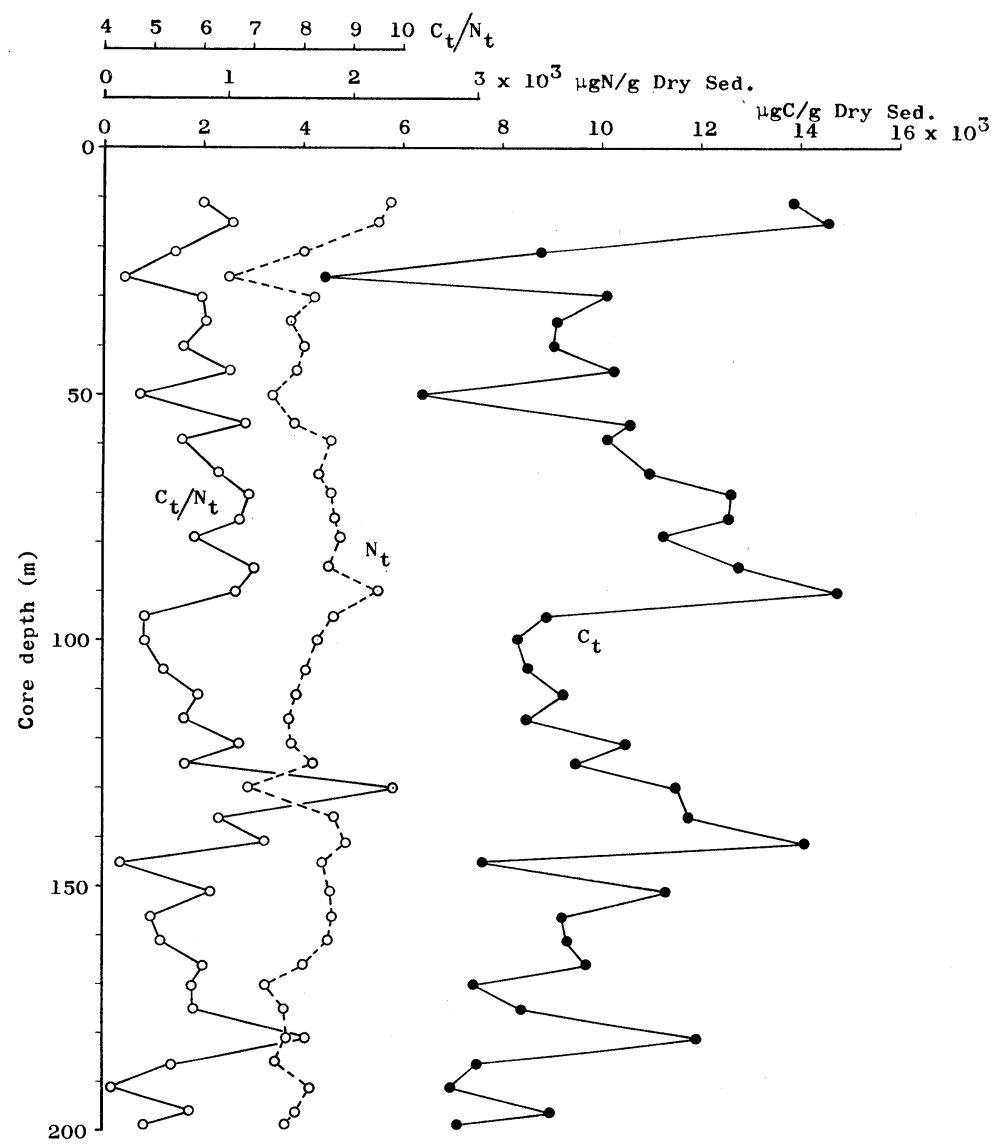

Fig. 2. Vertical distribution of total carbon and nitrogen in the core sample from Lake Biwa.

little water and dried up at $110^{\circ} \mathrm{C}$. The dried residue was ground to fine powder with an agate mortar.

Analytical instrument. The carbon and nitrogen in the samples were determined by using CHN-Corder MT 1s, Yanaco.

Preparation of combustion boat free from carbon, nitrogen and hydrogen. The combustion boat was made from a stainless tube (diameter: $8 \mathrm{~mm}$; length: $70 \mathrm{~mm}$ ), as is shown in Fig. 1 (a). The combustion boat was introduced into the combustion tube of the CHNCorder with a silica tube, as is shown in Fig. 1 (b), and the carbon, nitrogen, and hydrogen of the contaminated substances of the boat were determined according to the manual of the CHN-Corder. The determination was repeated on the same boat twice more in order to remove the contamination completely.

Preparation of copper oxide powder free from carbon, nitrogen, and hydrogen. Usually copper oxide powder contains some car- 


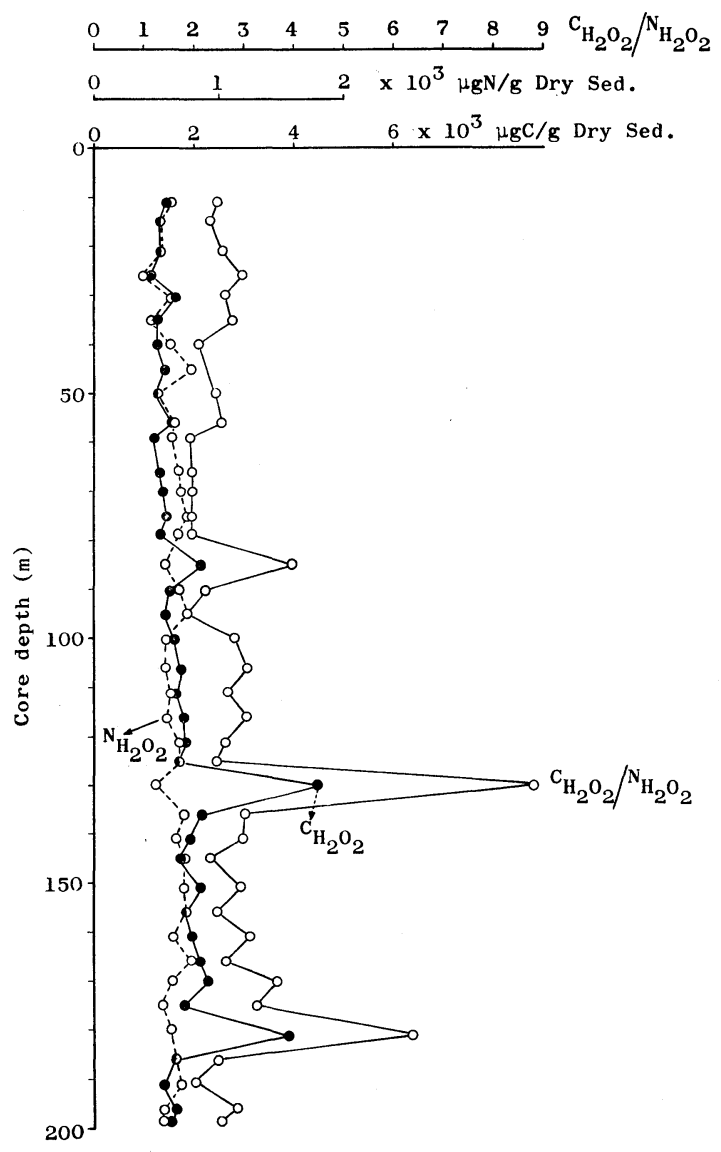

Fig. 3. Vertical distribution of total carbon and nitrogen in the core sample from Lake Biwa, which was treated with hydrogen peroxide.

bon, nitrogen and hydrogen compounds as impurities, therefore, in order of use the copper oxide powder as an oxidizing agent for the combustion of the organic matter in the samples, the impurities must first be removed. First, about $30 \mathrm{~g}$ of copper oxide powder was introduced into a combustion tube (diameter: $30 \mathrm{~mm}$; length: $600 \mathrm{~mm}$ ) made of silica tube. The tube was heated with an electric furnace at $850^{\circ} \mathrm{C}$ for about 1 hour under the running of oxygen to remove the greater part of the carbon, nitrogen, and hydrogen compounds from the copper oxide powder. Then about $1 \mathrm{~g}$ of the heated powder was placed in the combustion boat of stainless steel, and the residual carbon, nitrogen, and hydrogen in the heated powder were determined by using CHN-Corder MT 1s, Yanaco, according to its manual, these elements were thus removed from the powder. The determination of the carbon, nitrogen, and hydrogen and their removal were 


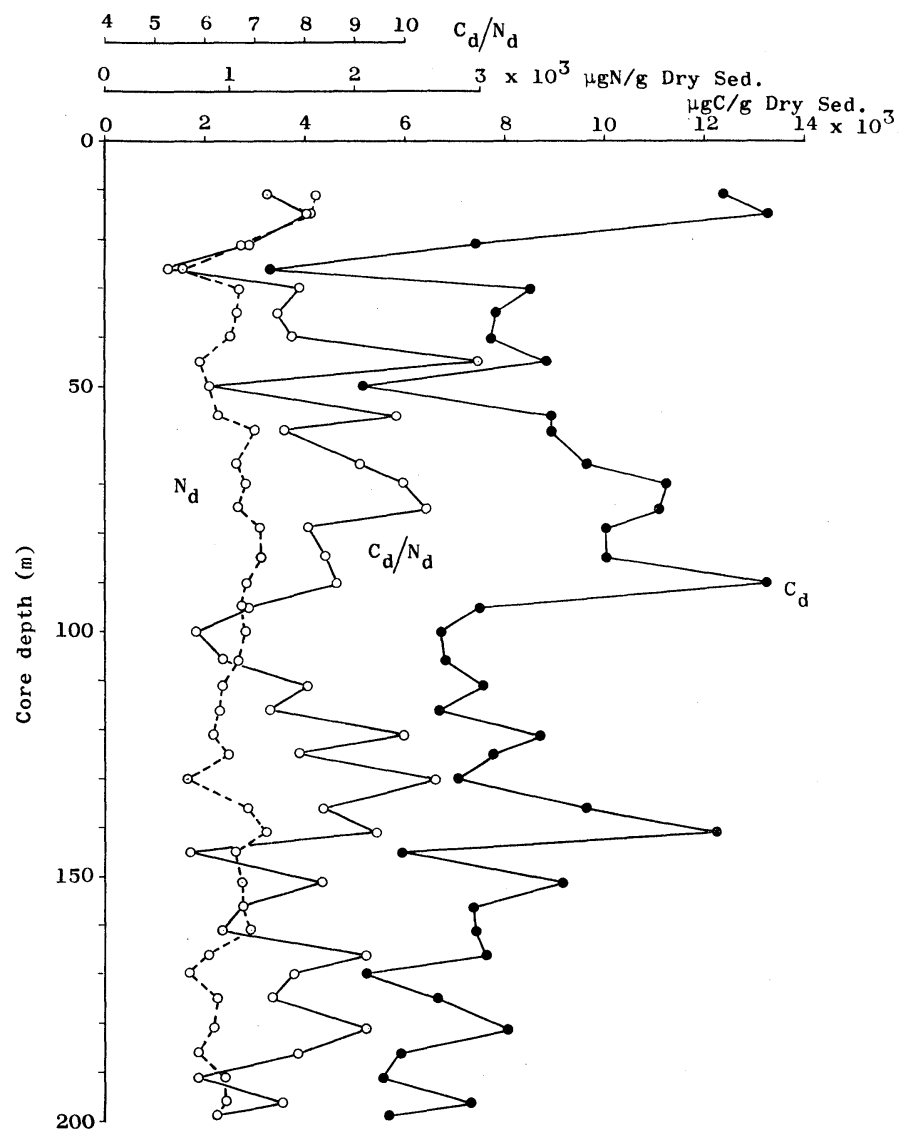

Fig. 4. Vertical distribution of $\mathrm{C}_{d}$ and $\mathrm{N}_{\mathrm{d}}$ in the core sample from

Lake Biwa. $\mathrm{C}_{\mathrm{d}}=\mathrm{C}_{t}-\mathrm{C}_{\mathrm{H}_{2} \mathrm{O}_{2}} ; \mathrm{N}_{\mathrm{d}}=\mathrm{N}_{\mathrm{t}}-\mathrm{N}_{\mathrm{H}_{2} \mathrm{O}_{2}}$

$\mathrm{C}_{t}$ : Total carbon in the sediment.

$\mathrm{N}_{\mathrm{t}}$ : Total nitrogen in the sediment.

$\mathrm{C}_{\mathrm{H}_{2} \mathrm{O}_{2}}$ : Total carbon in the sediment treated with $\mathrm{H}_{2} \mathrm{O}_{2}$.

$\mathrm{N}_{\mathrm{H}_{2} \mathrm{O}_{2}}$ : Total nitrogen in the sediment treated with $\mathrm{H}_{2} \mathrm{O}_{2}$.

repeated twice more on the same powder in order to remove these elements completely. Thus, copper oxide powder free from carbon, nitrogen, and hydrogen was prepared.

Procedure. The heated combustion boat was first weighed correctly, and then a 50-80-mg portion of the dried samples was placed in the boat, and it was weighed again in order to measure the sample correctly. To the sample a 50-80-mg portions of the copper oxide free from carbon, nitrogen, and hydrogen was added, and they were thoroughly mixed. The boat was then introduced into the combustion tube of the CHN-Corder with a silica tube, as is shown in Fig. 1 (b), and the carbon and nitrogen in the sample were determined 
according to the manual of the instrument. Acetoanilide and p-nitroaniline were used as the standard compounds for the determination.

Results. Fig. 2 shows the vertical distribution of total carbon $\left(\mathrm{C}_{t}\right)$ and nitrogen $\left(\mathrm{N}_{\mathrm{t}}\right)$ in the core sample. The total carbon includes the organic carbon and such inorganic carbon as carbonates, while the total nitrogen includes the organic nitrogen and such inorganic nitrogen as ammonium.

Fig. 3 shows the vertical distribution of the total carbon $\left(\mathrm{C}_{\mathrm{H}_{2} \mathrm{O}_{2}}\right)$ and total nitrogen $\left(\mathrm{N}_{\mathrm{H}_{2} \mathrm{O}_{2}}\right)$ in the core sample treated with hydrogen peroxide. The total carbon $\left(\mathrm{C}_{\mathrm{H}_{2} \mathrm{O}_{2}}\right)$ may consist mainly of carbonates and stable organic carbon. The total nitrogen $\left(\mathrm{N}_{\mathrm{H}_{2} \mathrm{O}_{2}}\right)$ may consist mainly of stable organic nitrogen or inorganic nitrogen compounds included in the clay mineral lattices.

Fig. 4 shows the vertical distribution of $\mathrm{C}_{\mathrm{a}}\left(=\mathrm{C}_{t}-\mathrm{C}_{\mathrm{H}_{2} \mathrm{O}_{2}}\right)$ and $\mathrm{N}_{\mathrm{d}}\left(=\mathrm{N}_{\mathrm{t}}-\mathrm{N}_{\mathrm{H}_{2} \mathrm{O}_{2}}\right)$ in the core sample. $\mathrm{C}_{\mathrm{d}}$ and $\mathrm{N}_{\mathrm{d}}$ principally indicate, respectiely, the organic carbon and the total amount of organic nitrogen and ammonium nitrogen in the sample. 